The Good, The Bad, and The Street:

Does 'street culture' affect offender communication and reception in restorative justice?

\author{
Roxanna Willis and Carolyn Hoyle
}

\begin{abstract}
This article examines whether and how 'street culture' affects offender communication and reception in restorative justice. Drawing on an archival dataset of police-led restorative justice conferences, we analyzed the relationship between street cultural capital and offenders' ability to communicate during restorative justice. We explored how offenders' social background, measured by street cultural capital, and/or communication abilities affects third-party perceptions of offender sincerity and their likelihood to reoffend. Results indicate that the embodiment of street cultural capital may affect offender participation in restorative justice. Socioeconomically disadvantaged offenders appeared more likely to experience communication difficulties, and were less likely to be perceived by third parties as sincere or willing to desist from offending. These findings are considered within a theoretical framework that draws on Bourdieu's concept of cultural capital, Skeggs' notion of inscription and Loftus' research on 'attitude tests'.
\end{abstract}

Keywords: restorative justice; race; street; cultural capital; Bourdieu; language 
Restorative justice processes can involve victims, offenders, and community members meeting to discuss the harms caused by offending behaviour (Marshall, 1999). They provide offenders with the opportunity to account for their behaviour, to apologise to victims, and possibly to make amends by undertaking an activity that symbolically or materially restores the harm (Von Hirsch et al., 2003). Advocates of restorative justice describe this as an empowering process, since it enables those affected by crime to directly participate in its resolution (Zehr, 2015). Others raise rights-based concerns that restorative justice could undermine offenders' rights to a fair trial, proportional sentencing, and protection from discrimination (Ashworth, 1993, 2001, 2002). While restorative justice research has considered the potential for power imbalance and discrimination related to gender (Hudson, 2002; Stubbs, 2007), ethnicity (Choi and Severson, 2009; Muna, 2017), age (Hayes, 2017; Suzuki and Wood, 2017), sexuality (Walters, 2014; Walters and Hoyle, 2010), and disability (Littlechild, 2011; Snow and Sanger, 2015), the impact of socioeconomic background has received limited empirical attention.

This article revisits an archival dataset of police-led restorative justice conferencing in the UK, and examines whether discrimination based on social background, measured in terms of 'street culture', is evident, reflecting on implications for restorative justice practice thereafter. Two cultural aspects of social background are of interest: how offenders verbally communicate in restorative justice conferencing and how offenders present physically. While these factors are also relevant to victims (Willis, 2018), due to space limitations, we focus on offenders.

Consideration of cultural difference in restorative justice has focused on ethnic difference. Early restorative scholarship examined the suitability of restorative justice for indigenous communities in New Zealand (Maxwell and Morris, 1993; Tauri and Morris, 1997) and Australia (Blagg, 2001; Daly, 2001; Nancarrow, 2006), among others. More recently, research in the European context has examined how racial differences may affect restorative processes (Albrecht, 2010; Campo et al., 2011; Gavrielides, 2014; Muna, 2017). Language barriers among non-native speakers emerged as a prominent theme, as well as challenges in managing different cultural communication styles (Albrecht, 2010; Campo et al., 2011). Similar concerns about communication difficulties have been raised in relation to the suitability of restorative justice for individuals living with disabilities, such as autism and other communication disorders (Littlechild, 2011; Snow and Sanger, 2015). Less obvious, however, are communication difficulties that relate to socioeconomic disadvantage, and how these intersect with other structural factors, such as ethnicity.

Sociological research indicates that socioeconomic background significantly affects how individuals communicate. We learn how to speak by engaging in language practices of the communities we grow up in, which ultimately influences our communication style, vocabulary, tone and much more (Bourdieu, 1991; Taylor, 2016). A valuable illustration of this can be found in Annette Lareau's (2011) study of parental practices among black middleclass and working-class families in America. Lareau found marked differences between the styles of communication cultivated in working-class and middle-class homes. Parents in middle-class homes tended to engage in continual conversation with their children, and as a consequence, their children became comfortable in giving lengthy descriptions, were able to enhance their vocabularies, and developed familiarity with more formalised ways of speaking. 
In contrast, working-class parents in Lareau's study prepared their children for very different socioeconomic conditions, and Lareau found language to perform a more functional role, with a preference for things to be kept short, and body language sometimes preferred over lengthy verbal description. Such classed-based communication difference could be significant in dialogue-strong processes like restorative justice.

In keeping with Lareau, and theoretically informed by the work of Bourdieu, we treat communication ability as part of an individual's stock of cultural capital, where culture includes skills that individuals acquire in the course of their lifetime (Lareau and Weininger, 2003; Swidler, 1986). Bourdieu explains that cultural capital can be objectified, institutionalised, and embodied $(1977,2000)$. When cultural capital is embodied, it forms part of an individual's habitus, which, crudely speaking, encompasses their learned dispositions and ways of being (Bourdieu, 1990). We propose that the embodiment of cultural capital is especially important to consider when assessing potential discrimination in criminal justice processes, since this will affect how participants present and are subsequently perceived by others.

Here, we use 'street' markers as an indication of disadvantage in light of Willis' (forthcoming) ethnographic finding that the more disadvantaged individuals are, the more they may be required to develop 'street capital' in order to survive and navigate tough spaces (Anderson, 1999; Lareau, 2011). 'Street culture' and 'street cultural capital' are concepts advanced by Sandberg and Pedersen as a particular subset of Bourdieusian cultural capital (2011; Sandberg, 2008, 2009). Inspired by the work of Elijah Anderson (1999) and others, 'street capital' refers to the dispositions, skills, and abilities that some individuals develop in order to flourish in tough spaces such as difficult neighbourhoods (for an overview see Shammas and Sandberg, 2016). Street skills might include developing an ability to identify plain-clothed police officers, acquiring knowledge and expertise in illicit enterprises, being prepared to use violence when required, among others (Sandberg and Pedersen, 2011: 29). We expect street cultural capital to be more often embodied by individuals growing up in tough environments, and consequently to form part of disadvantaged individuals' habitus.

The analysis is based on reconsideration of an archival dataset of police-led restorative justice conferences collected by Hoyle and colleagues (2002) between 1999 and 2000, which includes transcriptions of restorative justice conferences and interviews with victims, offenders, and facilitators in 54 cases. The data are analysed through the theoretical framework developed by Willis (forthcoming) during an ethnography of restorative justice conferencing in an English town between 2012 and 2013. We incorporate Sandberg and Pederson's ideas by looking for markers of street cultural capital in the dataset in order to assign street 'scores'. Offenders were categorised as having either a 'low' or 'high' street score, where a 'low' street score indicates that the offender is from a background of relative advantage, and a 'high' street score indicates that the offender is from a more disadvantaged background. Accordingly, we developed the following research questions:

1) Do street scores affect communication ability in restorative justice?

2) Do street scores affect how sincere offenders are perceived to be by third parties?

3) Do street scores affect third-party opinions about offender recidivism? 
4) Does communicative ability affect how sincere offenders are perceived to be by third parties?

5) Does communicative ability affect third-party opinions about offender recidivism?

Following a mixed-methods approach, first, the chi-squared method allows us to explore the relationship between two variables; and second, to overcome the limitations of this approach, such as failure to account for third variables, we incorporate qualitative analysis, based on deductive thematic coding.

The results of this exploratory analysis indicate that socioeconomic background, measured by street score, may affect offender communication ability in restorative justice: offenders categorised as having a high street score in our dataset appeared more likely to experience communication difficulties, although offenders with low street scores experienced difficulties too. Moreover, street scores seemed to be an indicator of how sincere third parties viewed offenders to be, and how third parties viewed the likelihood of reoffending: an offender with a high street score appeared more likely to be perceived by a third party as insincere and likely to reoffend. Communication scores were similarly indicative: an offender with low communication ability appeared more likely to be perceived by a third party as insincere and likely to reoffend. However, our analysis suggests that street scores may be a more significant factor for negative third-party judgements than communication ability per se. Race also emerges as a significant factor, which warrants attention in future research.

The analysis leads us to conclude that the type of cultural capital embodied by an offender could affect their communication in restorative justice and may lead to the forming of negative judgements. Due to design and sample size limitations of this study, we recommend that further research examines the impact of cultural capital and race in restorative justice more closely. If additional studies repeatedly find that social background appears to undermine fair treatment in restorative justice processes, then we suggest that procedural safeguards to protect against discrimination, unfair treatment, and disproportional criminal justice outcomes are essential.

\section{§1. Methodology}

The data analysed for this study derives from a 3-year project conducted by Hoyle and Young that involved a process and outcome analysis of a scripted model of police-led restorative conferencing. Following an initial 'action-research' study, Hoyle and Young observed and recorded 56 conferences and interviewed all, or most, participants immediately following the conference, again four months later, and-a proportion of them-a year after the conference. In total, they conducted 483 interviews, excluding 235 interviews conducted in relation to a further 23 conferences observed in their interim study. Interviews and observations sought information on participants' goals for participation; their views on the achievements of restorative conferences; procedural fairness; and the relationship between the quality of facilitation and satisfactory outcomes (Hoyle, 2006; Hoyle et al., 2002; Hoyle and Young, 2007). An under-explored aspect of the dataset was the relevance of social background, which warranted further analysis.

There were 64 offender case files in the archive dataset, which included interviews with stakeholders, offender self-reports, and transcripts of the restorative justice conference. The 
conference and interview transcripts were of the highest quality: completed by the researcher that observed the conference or conducted the interview, they were verbatim records of all communications, including pauses, sighs, other audible expressions and were accompanied by the researchers' notes on body language and demeanour. Cases were excluded from analysis when there were insufficient data to permit coding on at least two points of relevance to the study. Further, all drug offence cases were excluded from the study because there was ambiguity about the victims, and a tendency for offenders to assert that they had not done anything wrong, which impacted on sincerity. Applying these criteria for exclusion, 10 offender cases were excluded, leaving 54 cases for analysis.

The majority were youth offenders $(n=39)$, with only 15 percent adult offenders $(n=8)$. Ethnicity was not recorded in the data; however, comments in the research interviews and notes enabled us to identify a small number of black, Asian and ethnic minority (BAME) offenders $(n=4)$ : south Asian $(n=3)$ and black $(n=1)$. The gender ratio was two-thirds male $(n=38)$ and one-third female $(n=16)$. The majority of offences were theft-related $(n=22)$; followed by offences against the person $(n=13)$; then burglary $(n=6)$; taking a vehicle without the owner's consent $(n=3)$; driving offences $(n=3)$; criminal damage $(n=3)$; robbery $(n=2)$; and public order offences $(n=2)$.

\section{Coding the data}

In order to explore relationships between offenders' levels of advantage, offender participation in restorative justice, and how sincere offenders were perceived to be by third-parties, the data was coded in terms of 'street levels', 'levels of communicative ability', and 'perceptions of offender sincerity'. The data records street scores of 'high' and 'low', communication ability of 'good' and 'poor', and third-party perceptions of offender sincerity as 'sincere', 'unsure', 'insincere'. Third-party perceptions of the likelihood that offenders will reoffend were also measured as 'won't', 'might', 'will'. Each score was determined separately, in independent rounds of analysis, which required multiple stages of reviewing the case files.

\section{$\underline{\text { Street scores }}$}

Offenders were assigned a 'street' score ranging from 'low' to 'high'. Street scores were determined by reading through an offender's case file and assigning points when 'street' culture was evident. Where possible, these scores were triangulated with the opinions of other parties such as the facilitator and victims.

Street points were assigned based on criminological work that has developed cultural understandings of offender behaviour through the notion of 'street' capital (see, Anderson, 1999; Bourgois, 1995; Sandberg and Pedersen, 2011; Shammas and Sandberg, 2016; Stewart and Simons, 2006, 2010; Wacquant, 2007). Two aspects of legal cynicism were used as an indicator of 'street' culture: 1) offenders expressing anti-police sentiments, and 2) offenders following the norm of not telling authorities about the offences of others, expressed as 'no snitching' / 'no grassing'. Evidence of offenders subscribing to other street norms was also included within a street score, which incorporated the norm of using violence to respond to the threat of violence or actual violence; parents physically defending their children; physical discipline used in the home; references to repeat offending or 'trouble making'; and references to being in a gang. Other indicators included reference to offenders having chaotic family 
arrangements, living in a 'rough' area, and not engaging in school. Conversely, expressing positive attitudes towards the police, and engaging well in school, counted as minus street points.

At first, the street scores were divided into five levels of distinction. 'Low' was attributed to scores of $<1$; 'medium-low' to scores of 2; 'medium' to scores of 3; 'mediumhigh' to scores of 4; and 'high' to scores of $>5$. However, to allow for chi square analysis (where the totals of the rows and columns of the chi squared tables need to be above 1), the street scores were consolidated into two measures of 'high' and 'low'; high included scores of 4 and 5, and low was assigned to anything below this.

To illustrate how the coding was conducted, we draw on data relating to offenders A001 and A003, who were involved in the same 'non-dwelling burglary'. While the offenders were put through separate conferences, these were managed by the same facilitator, making them ideal comparators. Offender A001 was classified as having a 'high' street score. When asked what they thought about the police, A001 answered, '[t]hey're twats. I hate 'em. I hate the police [...] I hate them. I hate them. I fucking hate 'em.' A001 also subscribed to the street norm of 'no grassing': 'I'm not a grass basically. I'm not going to bring anyone's name into it.' Further reference was made to A001 living on a 'problem estate' and living in a chaotic family situation. In contrast, offender A003 was recorded as having a very low street score. A003 expressed positive views of the police, made known his intentions to attend university, and had a mother present who advocated on his behalf. During the restorative conference, the mother of A003 explained how she knew that something was wrong when her son came home because he displayed signs of having a 'terrible conscience' which 'manifests in eczema'. The mother continued to share how her son becomes upset when people throw litter, and she revealed that he is engaged in a lot of hobbies such as football and cricket, fundraising, and singing in the church choir. These co-offenders clearly presented very differently in the conference setting.

The opinions of others in each conference were considered in order to assess the accuracy of our street classification. Here, the categories of 'street' and 'decent' were assigned (Anderson, 1999), using the same indicators as above. There were also several references made by third parties in the dataset that challenged offenders' intelligence: 'if he had a brain cell he'd be dangerous'; 'he's just so stupid'; 'he obviously isn't a lad of high intelligence'. We assigned a street classification when offenders were described in this non-academic way, because, following Lareau and Weininger's interpretation of Bourdieu, the skills and abilities required to do well in school appear to be related to socioeconomic advantage, and, therefore, visible academic abilities may be (mis)interpreted as 'intelligence' whereas a lack of them could be (mis)interpreted as 'stupidity' (2003; Willis, 1977; Bourdieu and Passeron, 1977; Gillies and Edwards, 2006). Sometimes there were references to offenders being 'good' and 'bad', which were taken to indicate 'decent' and 'street' respectively. Notably, the street score assigned by the researchers' coding and the categorisation of third parties aligned closely.

There were limitations with this approach because the research project was not originally designed to discover 'street' characteristics. Consequently, some files had more information than others which may have contributed to higher street scores; for example, more information about an offender may have resulted in more street characteristics being found in the data. The triangulation approach helped to overcome gaps in the dataset. 
All of the offenders included in the study were assigned a street score $(n=54)$. Just under half of the dataset was classified as having high street scores, whereas just over half were classified as having a low street score. There was a higher percentage of female offenders with high street scores (50 percent) compared to male offenders (39 percent); however, the number of females included in the study $(\mathrm{n}=16)$ was low, and so this difference is not statistically significant.

\section{Communication Ability}

The files were then reanalysed to assign each offender a communication score of either 'good' or 'poor'. These scores were determined by analysing conference transcripts, assessing communicative ability during interviews, and relying on the observations by others about the offender's communicative abilities. Scores from 0 to 4 were initially given, 0 indicating poor and 4 indicating good communication. For the chi-square tests, these measures were consolidated into 'good' and 'poor' categorisations. Notably, there were four cases where an offender struggled to communicate but they were accompanied by a supporter who could communicate well; these cases were highlighted in the analysis and appeared to have relevance, as discussed below.

In addition to the conference transcriptions, third-party descriptions about how well offenders were able to communicate were taken into account. If the facilitator, victim, or original researcher used words like 'articulate' [B008], 'elegant' [B005] or 'well-spoken' [R010], this contributed to a 'good' communication score. Conversely, the following descriptions indicated poor communicative abilities: 'I didn't understand probably about 95 percent of what [the offender] said' [R001]; '[i]t was really difficult to get anything out of him because he was quite monosyllabic in his answers' [R013]; 'he had a finger in his mouth the whole time, picking his teeth erm, and, you know, was he, did he have a Scots accent?'[A016].

There were some limitations with this aspect of the coding. In one case, incomplete data meant that we were unable to assign a communication score. Moreover, verbatim transcriptions have limitations, since tone, speed, body language, accent, and so on are typically missing from the assessment (though pauses were recorded, and at times the tone of the expression was noted). Therefore, greater weight was given to third-party observations of offenders' communication during restorative conferences and where possible, these were triangulated with conference transcripts.

\section{Perceived Sincerity}

Assessments of third-party perceptions of offender sincerity were primarily based on facilitator feedback. In the interviews, facilitators were asked whether they thought offenders were generally sorry. Responses were coded as either 'sincere', where the facilitator was sure the apology was genuine; 'unsure', where the facilitator expressed uncertainty about the offenders' levels of sincerity; and 'insincere', where the facilitator explicitly doubted the offenders' sincerity. Victims' impressions of sincerity corresponded highly with facilitators' observations, but since data from victims was incomplete on this matter, only the facilitator scores are relied on here. In three cases, there were no facilitator interviews and therefore our scores are based on victims' observations. In total, perceived sincerity scores were assigned to 50 offenders. 


\section{§2. Results}

Table 1 in the appendix details the hypotheses developed to answer the five research questions and the results of the chi-squared tests calculated using SPSS software. In this section, we provide an overview of the chi-square results, which informed the qualitative data analysis, also presented.

\section{1) Do street scores affect communication ability in restorative justice?}

The chi-squared test indicates that there was a statistically significant association between offender street scores and offender communication abilities, $\chi^{2}(1)=11.710, p<.001$. The standardized residuals reveal that there was a relatively large positive result for offenders with low street scores who were recorded as speaking well $(z=3.4)$. This means that there were more offenders with low street scores who spoke well, and there were more offenders with high street scores who experienced communication difficulties, than the hypothesis for independence (the null hypothesis) predicts.

In total, only 36 percent of offenders were recorded as speaking well, whereas 64 percent had communication difficulties. This means offenders overall in the dataset were likely to struggle with communication. This may be due to age, given the group comprises young offenders, in accordance with research by Hayes (2017), and Suzuki and Wood (2017), which raises concern about the capacity of youth to fully engage in restorative justice processes. While only 45 percent of offenders with a low street score had communication difficulties, 91 percent of offenders with a high street score were recorded as having communication difficulties. Thus, 55 percent of offenders with a low street score were recorded as communicating well, compared to only 9 percent of offenders with a high street score.

Our qualitative data provides several examples to illustrate how communication ability may be related to socioeconomic background. In the methodology section, we outlined two offenders involved in a non-dwelling burglary: offender A001 had a 'high' street score and was recorded as has having 'poor' communication ability, whereas offender A003 had a 'low' street score and was recorded as having 'good' communication ability. In separate restorative justice conferences, both offenders were asked to explain 'what happened'. An extract from A001 conference transcription reads as follows:

A001: What you want me to talk you through what happened?

Facilitator: Please

A001: What we did?

Facilitator: Please

A001: [2 second pause] Broke into shed. Took the lawnmower out. Tried to get into someone's van and just got chased.

Facilitator: [...] What were your feelings as you broke into the shed? What was going through your mind? How did you feel?

A001: Alright.

Facilitator: Alright? [Sounding taken aback]

A001: Yeah. Don't know what you mean by that question.

Facilitator: Well we all have feelings um, I'm just trying to get at what you were actually feeling as you, you did that. 
A001: Get some money for it.

A001's answers were functional and literal, and he was explicitly confused with the style of questions. In contrast to A001's engagement with the restorative questions, A003 was much more fluent and familiar with this style of communication. In answer to the same question about what happened, A003 answered:

A003: Um someone came round to my house to call for me; ended up going out with them. They asked me to help lift this lawnmower into the back of a van. So reluctantly I helped.

Facilitator: Yeah. So you, you first became aware... you got a phone call did you?

A003: Yeah, I knew this friend was coming round and er, ended up saying, 'do you wanna come out' and I agreed to come out...

Facilitator: Mm

A003: ... He was parked up down the bottom of the road, and he said, 'oh, can you give us a hand to do this', and I was like 'no, no. I don't wanna help, I don't wanna help', and then I agreed to help, helped them.

Facilitator: $[\ldots]$ What... and what were thinking at the time when you were asked to do that? A003: This is where I live, [laughs at his own stupidity] I can't believe, you know, this is going on, this is just down the road, it's like... stupid...

Facilitator: [...] Anything else you thought at the...

A003: [2 second pause] Not really. [2 second pause] Well guilt.

Facilitator: Mm.

A003: If that's what you're getting at feeling-wise sort of thing.

Unlike A001, A003 is able to provide much fuller answers, and requires less prompting. Also, unlike A001, A003 is able to perceive what the facilitator is 'getting at', which helps him express a feeling of 'guilt'. Using greater expressive ability may be related to a different levels of socioeconomic advantage (Charlesworth, 2000; Lareau, 2011).

Notably, those with a low street score who had communication difficulties included three out of four offenders recorded as ethnic minority. One of these offenders was noted to have had a supporter present who spoke particularly well. Therefore, the intersection of socioeconomic background and ethnicity may be a relevant factor (Albrecht, 2010; Davidheiser, 2008; Gavrielides, 2014; Rodriguez, 2005). We return to this issue when presenting the results of question 4.

In the chi-squared tests, there was no gender significance. The analysis shows that boys were slightly more likely to speak well (42 percent) compared to girls ( 20 percent). While this aligns with Maxwell et al.'s research, which found that girls may find it particularly difficult to talk during restorative justice interventions (2003; Alder, 2000: 120), in our small dataset, the gender differences were insignificant statistically.

\section{2) Do street scores affect how sincere offenders are perceived to be by third parties?}

The results of the chi-squared test indicate that there were more offenders with 'high' street scores who were perceived as insincere by a third party than the hypothesis for independence predicts. While 61 percent of low street-score offenders were viewed as sincere by a third party, no high street-scoring offenders were. In contrast, 65 percent of street offenders were viewed 
as insincere, compared to 16 percent of offenders with a low street score. There were slightly more females who were considered as insincere ( 50 percent) than males ( 32 percent); however, this was not a statistically significant relationship.

Numerous qualitative examples illustrate how street characteristics appeared to influence facilitators' views about participants, including the following description of offender A016 and their supporter given by the restorative justice facilitator in interview:

He is a shit basically [...] the mother had shoes on that had one millimetre sole and the lad had on a track-suit that had been mended twelve times. They were both obviously really poor [...] they're really all thick as shit $[\ldots]$ dullards really, not getting anywhere with them $[\ldots]$ There was something about him that I didn't like and, erm, I don't think he was telling the truth.

The facilitator explicitly refers to the socioeconomic disadvantage of the offender and his mother. Moreover, on account of there being 'something about him', the facilitator expresses the belief that he was not telling the truth. Compare this to another facilitator's description of the offender and supporter in R019: 'he wasn't the sort of thuggy type of offender that they'd [the victims] already pictured. He had a supportive dad, they were both very softly spoken.' This description is indicative of a 'decent' offender (Anderson, 1999). When the facilitator was asked if they thought the offender was genuine, they replied: 'Yeah, yeah I do. Yeah.'

\section{3) Do street scores affect third-party opinions about offender recidivism?}

For the chi-squared test, there were more offenders with 'high' street scores whom third parties believed were certain to reoffend than the hypothesis for independence predicts. While 63 percent of offenders with low street scores were thought by a third party not to be at risk of reoffending, no offender with a high street score was believed likely not to reoffend. In contrast, 67 percent of street offenders were described by a third party as certain to reoffend, compared to 13 percent of offenders with a low street score. In the remaining cases, the facilitator was recorded as 'unsure'.

\section{4) Does communicative ability affect how sincere offenders are perceived to be by third parties?}

The chi-squared test indicates that there were more offenders with poor communication who were perceived by a third party as insincere than the hypothesis for independence predicts. Notably, the standardised residual (crudely, the difference between what was observed and what was expected) is lower here for offenders with good communication who were perceived to be sincere by a third party, compared to offenders with low street scores who had a higher standardised residual for third-party belief in sincerity. This may mean that a high street score is more predictive of a third party doubting an offender's sincerity than is poor communication.

The qualitative data similarly indicate that what is said may be less important than the way it is said, along with other mannerisms or indicators. Take, for example, case A018 which involved an offender classified as 'decent'. The facilitator in this case insisted that they always pay close attention to what is said in a conference: 'I'm very reserved in how I judge people, I'll come with an open, you know, sit there and listen [...] language tells you an awful lot about the person.' Despite this, the facilitator went on to explain that even though the offender did 
not 'face up' to the offence, and blamed his friend, he was 'really sweet', concluding that he was sincere and unlikely to reoffend. Notably, the offender did not apologise, and follow up interviews established that he had reoffending within a year.

Another stark illustration of how socioeconomic background appears to affect thirdparty judgements is in the non-dwelling burglary case mentioned above. The low street scoring offender (A003) refused to meet the victim and did not apologise. Nevertheless, the facilitator commented, 'I didn't actually hear him say "I'm sorry" at any point even though it was so obvious he was apologetic.' And then when the facilitator was asked if the offender was genuinely sorry, they replied 'yeah [...] I felt it was not his type of personality and he was sorry for what he'd done'. Contrast this to the victim's comments about the high street scoring offender (A001) in the same case who also had not apologised: 'I'll be honest with you, I don't think I would have believed it if he had said it [sorry].'

What is more, the qualitative data indicate that third-party assumptions about offender sincerity may be misguided. Case R010 is a prime example of how a 'decent' offender can overcome the limits of their poor communication and appear sincere while self-reporting to feel quite the opposite. The facilitator described offender R010 as coming from a 'restorative' family:

[His] dad is a teacher and his mum is a governor at his school, so they are quite involved in his education anyway. Um the way they think and the way they speak and the way they do things at home runs very much along the restorative justice lines and to be honest they probably, virtually conferenced this between themselves at home because of the way that they bring up their family and discipline their kids.

Despite the victim [a security guard at a store] also believing the offender to be 'not the sort of person' to shoplift (the offence he had been caught for), and believing the offender to be genuinely sorry, the offender described the conference in far different terms:

I didn't see why other people had got involved, because it was minor. But they turned up and made a big deal out of it. I felt a little bit angry towards him [the victim] or whatever, because it's all happened... obviously I've done wrong, and I should be punished. But he just sat there and listened to what I felt, and I didn't really like it.

Furthermore, in response to the security guard expressing fear for his safety every time he has to stop shoplifters, the offender remarked in the research interview: 'His job is security, if he doesn't like it, he should get a different job.'

Unlike the victim, the facilitator was uncertain about how genuine this offender's apology was, but doubted themself for feeling unsure when asked if the offender was genuinely sorry:

[7 second pause] Yes. But [4 second pause] he still retained an air of detachment when he was speaking [...] He didn't come across as... well he must have done because the store detective thought he was really genuinely sorry, so I guess he must have come across as... maybe I need a different job, I think I'm just getting a bit tired of it. I don't know! 
This illustrates how powerful an advantaged habitus can be: when someone exudes 'decency', it can influence judgements about sincerity, even among experienced police officers, and such social advantage may result in an offender being given the benefit of the doubt. The implications for citizen-police encounters on the street are clear, though beyond the scope of this study.

Three out of four offenders recorded as BAME had a low street score and struggled with communication. Of these, two were considered to be sincere (one of whom was helped by an articulate supporter), and the facilitator was uncertain in the third case. Thus, a low street score may mitigate poor communication, in relation to third-party perceptions of sincerity. However, ethnicity may intersect with socioeconomic background in unexpected ways (cf. Albrecht, 2010; Davidheiser, 2008; Gavrielides, 2014; Muna, 2017).

The two BAME offenders with a low street score who were considered to be sincere, despite having communication difficulties, were male and seemingly from south Asian backgrounds. The facilitators' judgements of these offenders as sincere may have been linked to racial assumptions. For example, in case A009, the facilitator commented:

I thought the sister was good ... only 20 , but she was quite mature I thought, and said, well exactly the right things really, that it had brought embarrassment, shame upon the family, you don't do things like this in our family, it's affected all the larger family.

Facilitators mentioned shame in all three cases that involved south Asian offenders; in two cases, the notion of shame was first raised by the offender's family, but it one case the facilitator inferred shame from a father's repeated apologies throughout the conference. Despite the male offender A009 struggling to speak, because of his sister's ability to communicate on his behalf during the conference, the facilitator concluded: 'I felt because she was a decent... it was a genuine nice family that fell foul on this occasion.' Here, race may have contributed to positive assumptions being made. Notably, the data were collected before the 2001 attacks on the World Trade Centre, and hence prior to the rise of crude racial stereotyping against Asian people since then.

The third offender recorded as BAME (R001), with a 'low' street score, and whose sincerity the facilitator could not ascertain, was female and, based on comments made, was likely to be black-described by one victim as 'the dark-skinned girl' and 'the young coloured girl'. A second victim offered the following opinion:

[R001's supporter] mentioned her colour once in the interview, and I don't know how, this is not a racist comment, far from it, I'm the last person to be racist, I'm not even pure English myself, um, but many West Indian boys have a huge chip on their shoulder, they think they are being persecuted because they are black, not because of what they have done. Now I don't think [R001] had that attitude but I could see a situation where I know children I have taught who if you say 'don't do that', unless they know you're not picking on them because they're black, nevertheless they say 'you're picking on me because I'm black', now that could arise. I think the victims certainly need to be aware of that possibility if they're not used to dealing with young children, black children especially. 
The victim in this case suggests that black offenders may wrongfully claim to be the victims of racism, which is something that victims in other cases need to be made aware of. Ironically, the victim further implies that, although offender R001 did not seem to have 'that attitude', nonetheless because she was black, the possibility arises that she might assume she was being treated differently; a likelihood which the victim believed increases for boys of West Indian ethnicity. All three victims in this case did not think R001 was sincere, and the facilitator was unsure. Consequently, race may have markedly influenced third-party perceptions of offender sincerity in this restorative justice encounter, and conceivably in others, though our data do not allow further exploration of this matter. In some circumstances, black skin could lead offenders with an otherwise low street score to be perceived as 'street' and experience negative treatment as a result (Blackledge, 2001; Bodovski, 2010; Reynolds, 2000; Rollock, 2014). It is therefore crucial to take race into account when analysing socioeconomic background.

A final point of note, there were four cases of offenders who struggled with communication, who had a low street score, and a supporter who spoke well (including one BAME case). Of these, three offenders were considered sincere, and one was recorded as uncertain. Therefore, having a supporter who speaks well on behalf of an offender may improve perceptions of sincerity. Of course, as we make clear above, not all parents are able or willing to do this (see Hoyle and Noguera, 2008) and this is likely to disadvantage 'street' offenders more than others.

\section{5) Does communicative ability affect third-party opinions about offender recidivism?}

The results of the chi-squared test indicate there were more offenders with poor communication who were perceived by a third party as likely to reoffend than the hypothesis for independence predicts. Notably, mirroring the results of 4 above, the standardised residual is lower here for offenders with poor communication skills, compared to offenders with high street scores, who were perceived by third parties as likely to reoffend. This means that high offender street scores may be more likely to predict a third party's belief in their reoffending than low communication scores. Thus, street scores may be more significant than communication ability (gender was not statistically significant).

\section{§3. Discussion}

In summary, the chi-squared tests indicate the following about offenders in our dataset. Offenders with high street scores and offenders with poor communication skills were more likely to be considered as insincere and likely to reoffend by third parties than offenders with low street scores and offenders with good communication ability. While there was an increased likelihood for offenders with high street scores to have poor communication, there were also offenders with low street scores who had poor communication, possibly because of the age of participants (Campo et al., 2011; Hayes, 2017; Suzuki and Wood, 2017). The chi-squared tests further indicate that high street scores may be more significant for third-party judgements of insincerity and belief in the likelihood of recidivism than poor communication ability. Moreover, it seems that a low street score, and a well-spoken offender-supporter, can improve third-party perceptions of offenders who struggle with the scripted restorative communication style. 
It therefore seems that the way an offender presents - whether it be street or decent may affect how third parties perceive them: what is said might be less important than who is saying it or how. The concept of 'inscription' developed by Beverley Skeggs $(1997,2004)$ can help to explain why street scores seem to matter most in these instances. Skeggs describes class, and the embodiment of cultural capital, as metaphorically inscribed on our bodies; it is in the way we dress, speak, stand, and sit. Our bodies carry our social background in ways that cannot be concealed. Therefore, it may be that when entering the room, offenders from disadvantaged backgrounds are instantly at a disadvantage in restorative justice interactions.

'Attitude tests', observed and developed by Bethan Loftus (2009) can help us to better understand why embodied cultural capital seems to matter more than what is said per se. In her ethnography of police patrol in England, Loftus observed police conducting tests to see if an offender had a good or bad attitude. If a suspect was compliant and respectful to the police in interactions, Loftus observed that they passed the test; however, if the offender was rude and uncooperative, they failed. Failing attitude tests could result in criminalisation, whereas passing them could lead to them being excused or given a warning. It appears that a similar type of testing occurred in the restorative justice data we analysed, which contributed to judgements about offenders sincerity and likelihood of reoffending.

Notably, decent offenders seemed more likely to pass attitude tests than street offenders. For example, in case A003 the facilitator explained 'I spoke to the mother [of the offender] and she was quite supportive, ... I had definite vibes that this was an embarrassment to basically a good family that their son had been involved in this'. Similarly, in B008, the facilitator reflected on the conference as follows:

I thought the meeting went very well. I thought that [the offender] participated and engaged very well and all the points that I wanted to bring out and address were there [...] He was apologetic and remorseful throughout the whole process [...] it was almost as if he had done it before and knew what to say.

When the facilitator was asked why he thought offender B008 was 'definitely' genuinely sorry, he said, 'I think his body language was indicative of that really and he was articulate in the way he spoke and my assessment as a police officer would be that that was a sign of the sincerity really in what he was saying.' Conversely, the facilitator in B002a felt the offender did not 'believe' in restorative justice, and the restorative justice session was less of a success. We also saw how a victim in R001, quoted above, expressed a racist belief that black offenders are more likely to have the wrong attitude. The assumption that decent offenders 'get' restorative justice, whereas street offenders do not, adds weight to claims that restorative justice is a model of justice that is more familiar to those from more advantaged social backgrounds (Delgado, 2000; Green et al., 2014; Levrant et al., 1999; Willis, 2018).

While our findings on attitude tests in our data are tentative, the extent to which they are apparent could be explained by the police-led nature of the conferences analysed in the study, since Loftus' 'attitude tests' also related to police-citizen encounters. It would be interesting to investigate whether these tests are apparent in other restorative justice processes not facilitated by the police. Moreover, since our classification of street culture includes cynical 
attitudes towards the police, high street-scoring offenders may be expected to fail attitude tests in this particular setting.

Although the BAME sample was small, when race was identified, it appeared to influence third-party judgements about offenders. Racial stereotyping was particularly apparent in the case of the single black offender. It is therefore imperative for restorative justice in particular, and British criminology in general, to engage meaningful with race scholarship (Parmar, 2017).

Being from a disadvantaged background - which we measured in terms of street scores - appears to increase the likelihood that an offender will be judged as insincere in restorative processes and more likely to reoffend. Since recidivism is the primary way to measure the success of restorative justice (Shapland et al., 2008), if facilitators believe that socioeconomically disadvantaged offenders are less receptive to the process, then they risk channelling them through harsher criminal justice processes, with inevitable repercussions should they reoffend (Rodriguez, 2005). Moreover, if socioeconomic background affects how sincere offenders are judged to be during restorative justice conferencing, then offenders from disadvantaged backgrounds risk being asked to complete more onerous restorative justice reparation agreements. Even if outcomes are not comparatively disproportionate, being subjected to discriminatory judgements for the duration of a restorative justice conference likely intensifies the punishment in the process of restorative justice (Daly, 2002; Young and Hoyle, 2003).

We offer preliminary thoughts for moving forwards. While in theory police involvement in restorative justice may lead to more restorative policing, the role and culture of policing, which necessitates hasty judgements about people, is likely to clash with restorative values. However, it should not be assumed that facilitators from other organisations or from the same socioeconomic or cultural backgrounds as offenders will have a better understanding of the structural effects of inequality or be more sympathetic (Rosenblatt, 2015). In fact, social distinctions may be drawn even sharper between those closest in social space (Ahmed, 2000; Sayer, 2005; Skeggs, 1997). What may be needed is in-depth training and education for all facilitators about the ways socioeconomic disadvantage affects how individuals present and communicate. Part of this training could involve encouraging each participant to reflexively engage with their own class position, their privileges and disadvantages, and reflect on how these might impact on a restorative conference. Ultimately, of course, overcoming structural power imbalances requires wider societal reform.

\section{§4. Concluding Remarks}

This study suggests that communication ability affects how sincere third parties perceived offenders to be, and social background (measured as 'street scores') might be an even greater indicator of how third parties perceive offender sincerity. We propose that this is because cultural capital is inscribed upon the body, visibly present for all to judge (Skeggs, 2004). Therefore, we suggest that offenders are judged for what they are, beyond what they say, and something akin to an attitude test may occur in restorative settings (Loftus, 2009). Such tests appear to weigh heavily on offenders who have embodied street culture, particularly racial minorities. In its current state, restorative justice risks exposing participants from 
disadvantaged backgrounds to negative third-party judgements and, in turn, disproportionate interventions. Consequently, we provisionally suggest moving away from police-led facilitation, training facilitators in the effects of socioeconomic inequality, and encouraging all participants in restorative justice to reflect on their social positions and (dis)advantages.

The main limitations of this study-small sample size and a dataset not designed to test the hypotheses-should be addressed by future research. Ethnicity, which we had only limited data on, must be taken seriously in further research on discrimination in restorative justice. A larger-scale project designed to use regression analysis and produce generlisable data could overcome the limitations of the chi-squared method, which only measures two variables; then the relationship between cultural capital, race and age could be better investigated. We hope that this study can offer a basis for such projects moving forwards. 
H1: Offender street scores and offender communication abilities are not independent. The higher the offender street score, the higher the level of offender communication difficulties.

\begin{tabular}{llll}
\hline \multicolumn{5}{c}{ Communication Ability } \\
\cline { 2 - 4 } Street Score & Good & Poor & Total \\
\hline Low & $17(3.4)$ & $14(-3.4)$ & 31 \\
High & $2(-3.4)$ & $20(3.4)$ & 22 \\
\hline Total & 19 & 34 & 53 \\
\hline
\end{tabular}

H2: Offender street scores and third-party perceived levels of offender sincerity are not independent. The higher the offender street score, the less sincere offenders are perceived to be by third parties.

\begin{tabular}{|c|c|c|c|c|}
\hline & \multicolumn{4}{|c|}{ Third-Party Perceived Offender Sincerity } \\
\hline Street Score & Sincere & Unsure & Insincere & Total \\
\hline Low & $19(4.7)$ & $7(-1)$ & $5(-3.7)$ & $\overline{31}$ \\
\hline High & $0(-4.7)$ & $8(1)$ & $15(3.7)$ & 23 \\
\hline Total & 19 & 15 & 20 & 54 \\
\hline
\end{tabular}

H3: Offender street scores and third-party belief that offender will reoffend are not independent. The higher the offender street score, the more likely the third party will believe the offender will reoffend.

\begin{tabular}{lllll}
\hline \multicolumn{5}{l}{ Third-Party Perceived Reoffender Likelihood } \\
\hline Street Score & Wont & Might & Will & Total \\
\hline Low & $19(4.6)$ & $7(-.8)$ & $4(-3.9)$ & 30 \\
High & $0(-4.6)$ & $7(.8)$ & $14(3.9)$ & 21 \\
\hline Total & 19 & 14 & 18 & 51 \\
\hline
\end{tabular}

H4: Offender communication ability and third-party perceived levels of offender sincerity are not independent. The better the offender communication ability, the sincerer offenders are perceived to be by third parties.

\begin{tabular}{|c|c|c|c|c|}
\hline Communication & Sincere & Unsure & Insincere & Total \\
\hline Poor & $7(-3.1)$ & $9(-.4)$ & $18(3.5)$ & 34 \\
\hline Good & $12(3.1)$ & $6(.4)$ & $1(-3.5)$ & 19 \\
\hline Total & 19 & 15 & 19 & 53 \\
\hline
\end{tabular}

H5: Offender communication ability and third-party belief that offender will reoffend are not independent. The better the offender communication ability, the less likely a third party will believe that the offender will reoffend.

Third-Party Perceived Reoffender Likelihood

\begin{tabular}{lllll}
\hline Communication & Wont & Might & Will & Total \\
\hline Poor & $7(-3.1)$ & $10(.7)$ & $15(2.6)$ & 32 \\
Good & $12(3.1)$ & $4(-.7)$ & $2(-2.6)$ & 18 \\
\hline Total & 19 & 14 & 17 & 50
\end{tabular}




\section{References}

Ahmed S (2000) Strange Encounters. Routledge.

Albrecht B (2010) Multicultural challenges for restorative justice: Mediators' experiences from Norway and Finland. Journal of Scandinavian Studies in Criminology and Crime Prevention 11(1): 3-24.

Alder C (2000) Young Women Offenders and the Challenge for Restorative Justice. In: McLaughlin E, Fergusson R, Hughes G, et al. (eds) Restorative Justice: Critical Issues. Sage Publications.

Anderson E (1999) Code of the Street. NY: Norton.

Ashworth A (1993) Some Doubts about Restorative Justice. Criminal Law Forum 4(2).

Ashworth A (2001) Is Restorative Justice the Way Forward for Criminal Justice. In: McLaughlin E, Fergusson R, Hughes G, et al. (eds) Restorative Justice: Critical Issues. Sage Publications.

Ashworth A (2002) Responsibilities, rights and restorative justice. British Journal of Criminology 42.

Blackledge A (2001) The wrong sort of capital? Bangladeshi women and their children's schooling in Birmingham, U.K. International Journal of Bilingualism 5(3): 345-369.

Blagg H (2001) Aboriginal Youth and Restorative Justice: Critical Notes from the Australian Frontier. Restorative Justice for Juveniles: Conferencing, mediation and circles: 227242.

Bodovski K (2010) Parental practices and educational achievement: social class, race, and habitus. British Journal of Sociology of Education 31(2): 139-156.

Bourdieu P (1977) Outline of a Theory of Practice. CUP.

Bourdieu P (1990) The Logic of Practice. Cambridge: Policy Press.

Bourdieu P (1991) Language and Symbolic Power. Cambridge: Policy Press.

Bourdieu P (2000) Pascalian Meditations. California: SUP.

Bourdieu P and Passeron J-C (1977) Reproduction in Education, Society and Culture. [1970]. London: Sage.

Bourgois P (1995) In Search of Respect: Selling Crack in El Barrio. Cambridge: CUP.

Campo J del, Vila R, Marti J, et al. (2011) Mediation among young immigrants in the juvenile penal justice system. Journal of Social Work 12(5): 491-509.

Charlesworth SJ (2000) A Phenomenology of Working-Class Experience. Cambridge: CUP. 
Choi JJ and Severson M (2009) Toward a culturally competent restorative justice practice framework: A focus on Asian Americans. Families in Society: The Journal of Contemporary Social Services 90(4): 399-406.

Daly K (2001) Conferencing in Australia and New Zealand: Variations, Research Findings, and Prospects. In: Morris A and Maxwell G (eds) Restorative Justice for Juveniles: Conferencing, Mediation and Circles. Hart.

Daly K (2002) Restorative justice: The real story. Punishment \& Society 4: 55.

Davidheiser M (2008) Race, worldviews, and conflict mediation: Black and white styles of conflict revisited. Peace \& Change 33(1): 60-89.

Delgado R (2000) Prosecuting violence: A colloquy on race, community, and justice. Stan. L. Rev. 52: 751-1865.

Gavrielides T (2014) Bringing Race Relations Into the Restorative Justice Debate An Alternative and Personalized Vision of "the Other". Journal of Black Studies 45(3): 216-246.

Gillies V and Edwards R (2006) A qualitative analysis of parenting and social capital: comparing the work of Coleman and Bourdieu. Qualitative Sociology Review 2(2).

Green S, Johnstone G and Lambert C (2014) Reshaping the field: building restorative capital. Restorative Justice 2(1): 43-63.

Hayes H (2017) Emotion and Language in Restorative Youth Justice. In: The Palgrave Handbook of Australian and New Zealand Criminology, Crime and Justice. Springer, pp. 407-419.

Hoyle C (2006) Policing and restorative justice. In: Johnstone G and Ness DWV (eds) Handbook of Restorative Justice. Oxon: Routledge.

Hoyle C and Noguera S (2008) Supporting Young Offenders Through Restorative Justice: Parents as (In)Appropriate Adults. British Journal of Community Justice 67(6).

Hoyle C and Young R (2007) Restorative Justice: Assessing the Prospects and Pitfalls. In: The Handbook of the Criminal Justice Process. Oxford: OUP.

Hoyle C, Young R and Hill R (2002) Proceed with Caution: An Evaluation of the Thames Valley Police Initiative in Restorative Cautioning. Joseph Rowntree Foundation.

Hudson B (2002) Restorative Justice and Gendered Violence: Diversion or Effective Justice? Brit. J. Criminol 42: 616.

Lareau A (2011) Unequal Childhoods: Class, Race, and Family Life. 2nd ed. Berkeley: University of California Press. Available at: ProQuest Ebook Central (accessed 1 September 2016).

Lareau A and Weininger EB (2003) Cultural capital in educational research: A critical assessment. Theory and Society 32(5-6): 567-606. 
Levrant S, Cullen FT, Fulton B, et al. (1999) Reconsidering restorative justice: The corruption of benevolence revisited? Crime \& Delinquency 45(1): 3-27.

Littlechild B (2011) Conflict resolution, restorative justice approaches and bullying in young people's residential units. Children \& Society 25(1): 47-58.

Loftus B (2009) Police Culture in a Changing World. OUP.

Marshall TF (1999) Restorative Justice: An Overview. Home Office, London.

Maxwell G, Kingi V, Morris A, et al. (2003) Differences in how girls and boys respond to family group conferences: preliminary research results. In: Walgrave L (ed.) Repositioning Restorative Justice. Willan Publishing.

Maxwell GM and Morris A (1993) Family, Victims and Culture: Youth Justice in New Zealand. Available at:

https://www.ncjrs.gov/App/abstractdb/AbstractDBDetails.aspx?id=153560 (accessed 6 October 2016).

Muna S (2017) Restorative justice and black, Asian and minority ethnic children in the youth justice system. A Restorative Justice Council research report. London: Restorative Justice Council.

Nancarrow H (2006) In search of justice for domestic and family violence Indigenous and non-Indigenous Australian women's perspectives. Theoretical Criminology 10(1): $87-106$.

Parmar A (2017) Intersectionality, Race and British Criminology: Are we there yet? Theoretical Criminology 35.

Reynolds T (2000) Black women and social-class identity. Cultural studies and the working class. Subject to change: 82-93.

Rodriguez N (2005) Restorative Justice, Communities, and Delinquency: Whom Do We Reintergrate. Criminology \& public policy 4(1): 103.

Rollock N (2014) Race, Class and 'The Harmony of Dispositions'. Sociology: 0038038514521716.

Rosenblatt F (2015) The Role of Community in Restorative Justice. NY : Routledge.

Sandberg S (2008) Street capital: Ethnicity and violence on the streets of Oslo. Theoretical Criminology 12(2): 153-171.

Sandberg S (2009) Symbolic capital and linguistic practice in street culture. University of Bergen, Norway. Available at: http://bora.uib.no/handle/1956/3750.

Sandberg S and Pedersen W (2011) Street Capital: Black Cannabis Dealers in a White Welfare State. UK: Policy Press.

Sayer A (2005) The Moral Significance of Class. CUP. 
Shammas VL and Sandberg S (2016) Habitus, capital, and conflict: Bringing Bourdieusian field theory to criminology. Criminology and Criminal Justice: 1748895815603774.

Shapland J, Atkinson A, Atkinson H, et al. (2008) Does restorative justice affect reconviction? The fourth report from the evaluation of three schemes. Ministry of Justice Research Series 10/08.

Skeggs B (1997) Formations of Class \& Gender: Becoming Respectable. London: Sage.

Skeggs B (2004) Class, Self, Culture. London: Routledge.

Snow PC and Sanger DD (2015) Restorative justice conferencing and the youth offender: Exploring the role of oral language competence. International Journal of Language \& Communication Disorders: 1-10.

Stewart EA and Simons RL (2006) Structure and culture in African American adolescent violence: A partial test of the "code of the street" thesis. Justice Quarterly 23(1): 133.

Stewart EA and Simons RL (2010) Race, Code of the Street, and Violent Delinquency: A Multilevel Investigation of Neighborhood Street Culture and Individual Norms of Violence. Criminology 48(2): 569-605.

Stubbs J (2007) Beyond apology? Domestic violence and critical questions for restorative justice. Criminology and Criminal Justice 7: 169.

Suzuki M and Wood WR (2017) Is restorative justice conferencing appropriate for youth offenders? Criminology \& Criminal Justice: 1748895817722188.

Swidler A (1986) Culture in action: Symbols and strategies. American sociological review: 273-286.

Tauri J and Morris A (1997) Re-forming justice: The potential of Maori processes. Australian \& New Zealand Journal of Criminology 30(2): 149-167.

Taylor C (2016) The Language Animal. HUP.

Von Hirsch A, Ashworth A and Shearing C (2003) Specifying aims and limits for restorative justice: A 'making amends' model. Restorative justice and criminal justice: Competing or reconcilable paradigms: $21-41$.

Wacquant L (2007) Urban Outcasts: A Comparative Sociology of Advanced Marginality. Polity Press.

Walters M and Hoyle C (2010) Healing harms and engendering tolerance: The promise of restorative justice for hate crime. Hate Crime: Concepts, policy, future directions. Willan Publishing.

Walters MA (2014) Hate Crime and Restorative Justice: Exploring Causes, Repairing Harms. OUP. 
Willis PE (1977) Learning to Labor: How Working Class Kids Get Working Class Jobs. NY: Columbia University Press.

Willis R (forthcoming) A Precarious Life: Understanding Class, Race and Conflict in a Deindustrialized Town. OUP.

Willis R (2018) 'Let's Talk About It': Why social class matters to restorative justice. Criminology \& Criminal Justice.

Young R and Hoyle C (2003) Restorative justice and punishment. In: McConville S (ed.) The Use of Punishment. Collompton: Willan.

Zehr H (2015) The Little Book of Restorative Justice: Revised and Updated. Skyhorse Publishing, Inc. 